\title{
On the Way Towards a Cognitive Historiography: Are We There Yet?
}

\author{
Dimitris Xygalatas ${ }^{1}$ \\ University of Connecticut, Storrs, CT/ Aarhus University, Denmark \\ xygalatas@mac.com
}

Keywords: cognitive science; historiography.

The publication of the first issue of the Journal of Cognitive Historiography (JCH) essentially aimed to mark the birth of a new interdisciplinary field, which is willing to take on the challenge of exploring how people in past societies thought and behaved. Cognitive Historiography thus becomes the latest addition to a number of inter-disciplinary areas which combine a subject matter from the humanities with methods and theories from the cognitive sciences, such as Cognitive Linguistics, Cognitive Anthropology, Cognitive Archaeology, Cognitive Semiotics, and others. In what follows I will offer a critical assessment of Cognitive Historiography as an emergent field, and particularly as it is represented in the inaugural issue of JCH.

For someone who works between the humanities and the cognitive sciences as I do, the emergence of this new research area is a very exciting development. For if the humanities are to survive in the modern academia, they need to keep up with theoretical and methodological developments in other disciplines, and certainly with scientific approaches to the study of human nature. Postmodernism has had its run, but in its obsessive focus on deconstruction it forgot to be constructive, failing to make any incremental contribution to our empirical knowledge of the world. In its extreme version, it dragged many humanistic disciplines down a stagnating path, infusing them with a nihilistic and self-defeating, not to mention deeply

1. Dimitris Xygalatas holds a joined appointment between the Department of Anthropology at the University of Connecticut and the Interacting Minds Centre at Aarhus University. He has previously held positions at Princeton and Masaryk University, where he served as Director of the Laboratory for the Experimental Research of Religion. 
hypocritical mentality; after all, why would someone who staunchly and publicly denounces any form of authority and denies the very possibility of any objective knowledge collect a professorial pay check by an academic establishment (Xygalatas 2012)?

That is not to say that interpretivism and relativism are not useful tools for enriching our perspective of the world. To the contrary, they are and should be an indispensable part of university curricula (and not just in humanistic disciplines), to the extent that they offer a critical evaluation of academic and scientific knowledge production. However, science (not only in its strict sense of the "natural sciences" but also in its broader etymological sense as an organized body of knowledge) is a progressive discourse. And no progress in our knowledge of the world can come without some commonly accepted epistemological commitments, which can be challenged and improved upon through the formulation of falsifiable hypotheses and the conduct of empirical testing (Bereiter 1994). Furthermore, progress in any academic field is incomplete without input from other fields, as Edward Slingerland (2014) argues in his article on Consilience in the inaugural issue of $\mathrm{JCH}$ (see also Slingerland and Collard 2012; Wilson 1998). Cognitive Historiography aspires to make a contribution on both of those fronts: by creating consilience between the historical and the cognitive disciplines, and by combining theoretical and interpretative with explanatory and empirical treatments of textual material.

The first steps of this new research area are reminiscent of the situation during the early days of a field I am more familiar with, the Cognitive Science of Religion, a situation which is both encouraging and unsatisfactory. One the one hand, it is encouraging to see a group of historians who are willing to engage with developments outside of their own field - and comfort zone - in order to enrich their understanding of their subject matter. On the other hand, a review of the current state of the art in this research area, particularly as it is reflected in the first issue of $J C H$, shows that there is a long way to go before Cognitive Historiography can be legitimately considered as an established academic sub-discipline.

The first editorial of $\mathrm{JCH}$ delineates the editors' vision for the journal. Their aim is to "embrace the broad interdisciplinary swathe of historical and cognitive scholarship and to encourage novel interconnections", while also endeavouring to "support collaboration in what is an experimental, interdisciplinary field" (Eidinow and Martin 2014: 8). In my reading, these pronouncements primarily invoke three key concepts which the authors hope will enrich cognitive historiography: "interdisciplinarity", "collaboration", and "experimentation". I am fully sympathetic to these goals. But does the volume satisfactorily serve these stated goals and standards? 


\section{Three Key Concepts for Cognitive Historiography}

The first concept (interdisciplinarity) is fundamental for Cognitive Historiography by its very nature as a research area stemming from a combination of humanistic and scientific approaches, and particularly since one of its constituent parts (Cognitive Science) is radically interdisciplinary itself. Thus, as the editors already note in their introduction, if this research area is to thrive, the relationship between historical and cognitive approaches must be deep and encompassing rather than merely superficial. However, although all authors bring cognitive theory to the forefront of their interpretative treatment of their material, the deep interdisciplinary interconnection that the editors envision does not materialize in the majority of the contributions. With few exceptions (Griffith 2014; Lundhaug 2014), cognitivescientific literature is vastly underrepresented in the volume. And where it is present, such literature is often outdated and coming from the fringes rather than the state-of-the-art in cognitive science.

Interdisciplinarity is directly linked to the second key term (collaboration), as the editors also note in their introduction. However, the editorial is the only co-authored piece in the entire volume. This is not a trivial issue. Interdisciplinarity can be perceived in two different ways: a scholar may do interdisciplinary work by combining training, expertise, or methods from two or more academic disciplines. The flip side of this is obviously the difficulty of keeping up with developments in more than one discipline, and the risk of becoming a jack of all trades and master of none. A different - and much more powerful - type of interdisciplinary research involves people from various disciplines pulling in their collective expertise to work on collaborative projects. This collaborative working model is still new to the humanities, although it is proving to be very successful in most fields in the natural, health, and social sciences. In the current academic context of increasing specialization and ever-accelerating rates of knowledge production, the benefits of such a model can be enormous, resulting in research programmes whose collective strength is much greater than the sum of their parts. Surely, historians who wish to engage in cognitive historiography would benefit from working closely with cognitive scientists who have similar interests in past minds. This is most obvious in the case of Griffith's contribution to the first $J C H$ issue (2014), which in my view exemplifies some of the best merits and some of the most serious flaws of the issue at the same time.

In this article, Griffith examines the role and importance of a particular iconographic element of the Roman Mithraic Mysteries, depicting the slaying of a bull by Mithras, which was presented to those being initiated into 
the cult of this deity. Having discussed some of the proposed interpretations about the significance of this icon for doctrinal transmission in the context of the initiatory ceremony, she lays out specific hypotheses pertaining to the memorability of various items of the iconographic representation. She then goes on to design an experimental study, exposing subjects to various levels of narrative exegesis to test what level would best facilitate recall of the iconographical scene.

The experiment is skillfully crafted and well-executed enough to pass muster in peer-reviewed psychology journals. Moreover, Griffith is careful to acknowledge the limitations of her methods and displays commendable awareness of current debates on conducting psychological experiments among student populations (Henrich et al. 2010). Having set the bar this high, the rest of the article spectacularly fails to clear it. The results section is limited to reporting mean values for a couple of variables and some visual graphs without even descriptive statistics for the rest. No inferential statistical analysis has been conducted whatsoever, which makes this section meaningless for testing the specific hypotheses that have been proposed. What is worse, the discussion section erroneously assumes that the differences presented confirm some of the proposed hypotheses, and claims such as "[recall was] much higher" (83) or that "the hypothesis...was proven" (85) are thrown around entirely unsubstantiated by the evidence presented. In fact, given the generally small differences reported (so small that they are often only found in the decimals) as well as the small sample size (15-16 subjects per group), it seems most likely that these very findings can be used to disconfirm rather than confirm the author's hypotheses.

This brings us back to the issue of interdisciplinary collaboration, and a problem which Edward Slingerland raises in the last - and in my view also the best - article of the issue. Slingerland (2014: 127) rightly warns of the dangers of the "lone wolf" model of research, still prevalent among scholars in the humanities, who have been trained to work in isolation and thus often miss out on the potential of collaborative work. In the case of Griffith's article, the problems outlined above could have been easily prevented by inviting a psychology student or colleague to perform a basic statistical analysis of the findings in exchange for co-authorship. Such a simple step (a matter of no more than a couple of hours for the needs of this paper) could have made the difference between a potentially great paper and a truly great one.

Finally, the third key concept that the editors stress is "experimentation". However, the majority of authors do not appear to take that concept as seriously. In fact, only Griffith and Slingerland seem to acknowledge the importance of this concept, which is not even mentioned anywhere else 
in the volume. This seems to be indicative of a broader misunderstanding with regards to the potential contributions of Cognitive Science to Cognitive Historiography. This misunderstanding is already apparent in the first paragraphs of the volume, where the editors repeatedly talk about this contribution in terms of theory alone. In fact, the editors never talk of the cognitive sciences but only of "cognitive theorizing", which they mistakenly identify as a "youthful discipline that crosses multiple subject barriers" (Eidinow and Martin 2014: 6). The discipline is of course not "cognitive theorizing" but "Cognitive Science", which is in fact very empirically driven. And while this might initially seem like a linguistic slip, it turns out to be characteristic of a view pervasive throughout the volume, i.e. that the contribution of the cognitive sciences to Cognitive Historiography is limited to theorizing about past minds.

\section{Three Ways of Using Experimental Approaches in Cognitive Historiography}

Admittedly, experimenting with dead minds is not an easy task. On the one hand, most historians were never trained in experimental methods, come from very different methodological traditions, and are used to employing very different ways of analysing their data. On the other hand, those who come from experimental sciences and are interested in past minds often lack contextual knowledge, philological expertise, and a more sophisticated reading of historical material (Slingerland 2014). The challenge for those on both of those sides is not to dilute their skills and expertise by trying to become polymaths, but to exploit and combine their strengths by working together. For this reason, the first two key concepts, "interdisciplinarity" and "collaboration", are a sine qua non for Cognitive Historiography.

Of course, experimenting with dead minds also presents intrinsic challenges, mainly arising from the fact that these dead minds belong to dead people, who are not available for taking part in experiments. What is the usefulness of the experimental method for Cognitive Historiography then? I will outline three examples of how historians might benefit from experimental work in their pursuit of a better understanding of past minds.

The first way is by looking at existing experimental evidence from living subjects to make inferences about past people. Despite disagreements in defining the exact time periods (Mellars 2006), it is an uncontroversial assumption among cognitive scientists that the mental and behavioural architecture of anatomically modern humans has not undergone any significant changes in historical times (the last few millennia). It is thus reasonable 
to assume that evidence on contemporary cognition can also illuminate past cognition. This is the simplest and easiest opportunity for historians to evaluate their own assumptions about past minds, however most contributors to the volume miss it. Instead of drawing from the wealth of existing empirical cognitive scientific evidence, they most commonly evoke cognitive theoretical models to support their own theoretical interpretations, and as interesting as those models might be, they are merely imposed to the subject matter without being tested.

The second way for cognitive historiographers to benefit from experimental methods is by providing hypotheses derived from their historical material to be tested experimentally, based on the same principle, that the study of living people can tell us what dead people might have been like. The only example of this approach in the volume is the article by Griffith (2014), who uses material derived from her historical record to design a psychological experiment in order to test cognitive historiographical hypotheses.

Finally, a third avenue for Cognitive Historiography is the use of natural experiments (Diamond and Robinson 2010). This approach consists in applying systematic quantification and statistical analysis of historical material. Although this method does not allow for the golden standard of random assignment and therefore cannot accurately determine causal relationships, it offers some unique advantages, such as the possibility for obtaining very large samples at low costs and avoiding ethical and practical pitfalls associated with living human subjects (Slingerland 2014). Thanks to these advantages, natural experiments are one of the most powerful tools for a variety of established scientific disciplines, such as for example epidemiology.

\section{The Potential of Cognitive Historiography}

As I argued at the beginning of this paper, the current state of the art in Cognitive Historiography is both encouraging and unsatisfactory. This situation does not constitute an anomaly, but reflects a particular developmental stage that any new discipline will inevitably go through before reaching maturity. It is most exciting that historians have initiated this movement, because historians are the ones who will need to spearhead it. The most important asset in this endeavour is an in-depth understanding of the subject matter, i.e. the contextual subtleties of the historical record, which will allow the formulation and evaluation of precise predictions. Building on this foundation, cognitive historiographers will need to engage in truly interdisciplinary, collaborative efforts while embracing the potential of quantitative hypothesis-testing. 
An excellent example of this approach can be found in the work of an interdisciplinary team consisting of archaeologists Jessica Munson and Jonathan Scholnick, linguist Martha Macri, and evolutionary anthropologist Marc Collard. By applying multi-relational network analyses of historical and archaeological records, this team conducted a series of natural experiments on various religious and sociopolitical aspects of pre-Hispanic Maya culture (Munson and Macri 2009; Munson et al. 2014; Scholnick et al. 2013). Another example is the work of evolutionary biologist Peter Turchin and classicist Walter Scheidel (2009), who combined formal modelling with archaeological and archival findings to explain demographic changes in the Roman Republic during the first century вСЕ based on historical data on coin hoards. The work of these scholars has been published in top-ranking journals in both the humanities and the sciences, showcasing the potential of a collaborative, interdisciplinary, and quantitative approach to history. This approach can prove a fruitful model for cognitive historiographers. By sharing expertise with other scholars and disciplines and combining diverse theoretical and methodological perspectives, they can engage in a mutually beneficial relation, the cumulative results of which will be far greater than the sum of its parts.

\section{References}

Bereiter, C. 1994. "Implications for Science, or, Science as Progressive Discourse”. Educational Psychologist 29(1): 3-12. http://dx.doi.org/10.1207/s15326985ep2901_1

Diamond, J., and J. A. Robinson. 2010. Natural Experiments of History. Cambridge, MA: Harvard University Press.

Eidinow, E., and L. H. Martin. 2014. "Editors' Introduction". Journal of Cognitive Historiography 1(1): 5-9. http://dx.doi.org/10.1558/jch.vli1.5

Griffith, A. 2014. "Dead Religion, Live Minds: Memory and Recall of the Mithraic Bull-slaying Scene". Journal of Cognitive Historiography 1(1): 72-89. http://dx.doi.org/10.1558/jch.v1 i1.72

Henrich, J., S. J. Heine and A. Norenzayan. 2010. “The Weirdest People in the World?” Behavioral and Brain Sciences 33(2-3): 61-83. http://dx.doi.org/10.1017/S0140525X0999152X

Lundhaug, H. 2014. "Memory and Early Monastic Literary Practices: A Cognitive Perspective". Journal of Cognitive Historiography 1(1): 98-120. http://dx.doi.org/10.1558/jch.v1 i1.98

Mellars, P. 2006. "Why Did Modern Human Populations Disperse from Africa ca. 60,000 Years Ago? A New Model". Proceedings of the National Academy of Sciences 103(25): 938186. http://dx.doi.org/10.1073/pnas.0510792103

Munson, J. L., and M. J. Macri. 2009. "Sociopolitical Network Interactions: A Case Study of the Classic Maya”. Journal of Anthropological Archaeology 28(4): 424-38. http://dx.doi.org/ 10.1016/j.jaa.2009.08.002

Munson, J., M. J. Macri and M. Collard. 2014. "Classic Maya Bloodletting and the Cultural Evolution of Religious Rituals: Quantifying Patterns of Variation in Hieroglyphic Texts". PLoS ONE 9(9): e107982. http://dx.doi.org/10.1371/journal.pone.0107982 
Scholnick, J. B., J. Munson and M. Macri. 2013. "Positioning Power in a Multi-relational Framework: A Social Network Analysis of Classic Maya Political Rhetoric”. In Network Analysis in Archaeology: New Approaches to Regional Interaction, ed. C. Knappett. Oxford: Oxford University Press, 95-124. http://dx.doi.org/10.1093/acprof:oso/9780199697090. 003.0005

Slingerland, E. 2014. "Toward a Second Wave of Consilience in the Cognitive Scientific Study of Religion”. Journal of Cognitive Historiography 1(1): 121-30. http://dx.doi.org/10.1558/ jch.vli1.121

Slingerland, E., and M. Collard. 2012. "Creating Consilience: Toward a Second Wave". In Creating Consilience: Integrating the Sciences and the Humanities, ed. E. Slingerland and M. Collard. New York: Oxford University Press, 3-40.

Turchin, P., and W. Scheidel. 2009. "Coin Hoards Speak of Population Declines in Ancient Rome". Proceedings of the National Academy of Sciences 106(41): 17276-79. http://dx.doi. org/10.1073/pnas.0904576106

Wilson, E. O. 1998. Consilience: The Unity of Knowledge. New York: Vintage.

Xygalatas, D. 2012. The Burning Saints: Cognition and Culture in the Fire-walking Rituals of the Anastenaria. London: Acumen. 